\title{
ANTI-INFLAMMATORY ACTIVITY OF SYZYGIUM AROMATICUM SILVER NANOPARTICLES: IN VITRO AND IN SILICO STUDY
}

\author{
RESLEE ELSA VARGHESE ${ }^{1}$, RAGAVAN ${ }^{1}{ }^{1}$, SARANYA SIVARAJ ${ }^{1}$, DASARARAJU GAYATHRI ${ }^{2}$, GOMATHI KANNAYIRAM ${ }^{1 *}$ \\ ${ }^{1}$ Department of Biotechnology, Dr. M.G.R Educational and Research Institute University, Chennai, Tamil Nadu, India. ${ }^{2}$ Centre of Advanced \\ Study in Crystallography and Biophysics, University of Madras, Guindy Campus, Chennai, Tamil Nadu, India. \\ Email: drgomathigopinathan@gmail.com \\ Received: 13 May 2017, Revised and Accepted: 09 August 2017
}

ABSTRACT

Objective: In the present study, antioxidant and anti-inflammatory activity of Syzygium aromaticum (clove) silver nanoparticles (clove AgNP's) was evaluated.

Methods: Gas chromatography-mass spectrometry technique was used to identify the compounds present in the aqueous extract of clove. Fourier transform infrared (FT-IR) analysis was done to characterize the clove silver AgNP's. 1,1-diphenyl-2-picrylhydrazyl (DPPH) assay was performed to evaluate the antioxidant property of nanoparticles $(0.05$ and $0.25 \mathrm{mg} / \mathrm{ml})$ and aqueous extracts $(0.05,0.1$, and $0.25 \mathrm{mg} / \mathrm{ml})$ of clove. The antiinflammatory property of the clove AgNP's was determined by inhibition of protein denaturation and downregulation of interleukin-1 beta. In silico molecular docking studies was performed using Schrodinger Maestro software.

Results: Eugenol was found to be highest with 16.27\%. The AgNP's exhibited dose-dependent antioxidant property. AgNP's scavenged $80 \%$ of radical at the concentration of $0.25 \mathrm{mg} / \mathrm{ml}$. The scavenging activity of AgNP's markedly increased when compared to aqueous extract at the same concentration. Inhibition of protein denaturation assay also revealed AgNP's showing the highest activity (66\%) when compared with drug aspirin (55\%) and aqueous extract (56\%). In the enzyme-linked immunosorbent assay (ELISA) method, AgNP's showed better inhibition (80\%) when compared to aqueous extract (60\%). Among 15 compounds, two compounds (eugenol and methyl 14-methylpentadecanoate) showed good glide energy, docking score, and hydrogen-bonded active site interactions with the protein interleukin-1 beta.

Conclusion: As AgNP's were more active than the aqueous extract, it may be considered for pharmacological activity against inflammatory disorders.

Keywords: Syzygium aromaticum, Antioxidant, Anti-inflammatory, Interleukin-1 beta, Molecular docking.

(c) 2017 The Authors. Published by Innovare Academic Sciences Pvt Ltd. This is an open access article under the CC BY license (http://creativecommons. org/licenses/by/4. 0/) DOI: http://dx.doi.org/10.22159/ajpcr.2017.v10i11.19904

\section{INTRODUCTION}

Inflammation is a common defensive mechanism against infection and injury. Innate and adaptive immune response is responsible for the inflammation. Apart from the protective role, chronic inflammatory response acts as a precursor for various metabolic disorders. Steroidal and non-steroidal drugs are being used to minimize the pathological effects of undesired inflammations [1]. However, prolonged usage of anti-inflammatory drugs causes various undesirable side effects and in turn damages organs such as liver and kidney. Due to this, there is a need for safe and potent anti-inflammatory drug. Diverse research is going on in developing efficient anti-inflammatory drugs from various sources such as medicinal plants, marine organisms, and synthetic drugs [2]. One popular approach used in the development of antiinflammatory drugs is through nanoparticle formation.

Traditional medicines such as Siddha and Ayurveda use inorganic ions in several herbal formulations to treat various chronic pathological disorders [3]. In this regard, efficient way for introducing the metal ions in the treatment of inflammation is through nanoparticle formation. Silver has been widely used in our traditional medicine for various applications. Modern methods in production of silver-based nanoparticle are tedious and also hazardous to the environment. Replacement of herbal extracts with chemicals in the production of silver particles is much beneficial and also reflects our traditional methods [4]. Apart from this herbal extracts, production of silver particles inculcate the beneficial alkaloids and flavonoids, and thereby enhances the efficacy of AgNP's.
Syzygium aromaticum (clove) has been traditionally used for the treatment of tooth disorders, indigestion, joint pains, etc. [5]. The recent studies show that clove possesses significant anti-inflammatory and antioxidant activities [6]. In this regard, the present study was focused to synthesize AgNP's using an aqueous extract of clove for anti-inflammatory activity. Combined effects of nanoparticle and herbal medicine will produce the valuable pharmacologically efficient anti-inflammatory product by balancing the problems associated with herbal medicine and nanomedicine.

\section{METHODS}

Chemicals and reagents

Silver nitrate and 2, 2-diphenyl-1-picrylhydrazyl (DPPH) were obtained from Sigma-Aldrich. Butylated hydroxyanisole (BHA) was purchased from Hi-Media Laboratories Pvt. Ltd. Solvents were purchased from Loba chemicals.

\section{Plant materials and extraction}

The aqueous extract was prepared based on the protocol [7] with minor modifications. Clove was obtained from local spice market. About $30 \mathrm{~g}$ of cloves was ground into a fine powder and soaked in distilled water in the ratio of 1:3 for 3 days with intermittent shaking. The extract was filtered using Whatman filter paper No. 1 and was dried using china dish covered with perforated aluminum foil. The dried extract was stored at $4^{\circ} \mathrm{C}$ until use.

Synthesis of clove AgNP's

The synthesis procedure was carried out based on the protocol [8]. About $1 \mathrm{ml}$ of clove aqueous extract was added to $10 \mathrm{ml}$ of $1 \mathrm{mM}$ 
silver nitrate solution with constant stirring for about $2 \mathrm{hrs}$ at room temperature. The reaction mixture was checked periodically for color change. After 2 hrs of incubation time, the yellowish-green color was observed, which was then centrifuged at $3000 \mathrm{rpm}$ for 10 minutes. The pellet contained the nanoparticles, which was separated and stored in a sterile Eppendorf's at $4^{\circ} \mathrm{C}$.

\section{Gas chromatography-mass spectrometry (GC-MS)}

GC-MS analysis was performed for the clove ethanol extract using GC SHIMADZU QP2010 system and as interfaced to a MS (GC-MS) equipped with Elite-1 fused silica capillary column (length: $30.0 \mathrm{~m}$, diameter: $0.25 \mathrm{~mm}$, film thickness: $0.25 \mu \mathrm{m}$ composed of $100 \%$ dimethylpolysiloxane). The ionization energy of $70 \mathrm{eV}$ was used and $99.99 \%$ helium gas was used as carrier gas at a flow rate of $1.51 \mathrm{ml} /$ minutes. About $2 \mu \mathrm{l}$ of sample was injected (split ratio: 20 ). The oven temperature was programmed from $70^{\circ} \mathrm{C}$ to $300^{\circ} \mathrm{C}$ for 10 minutes. Mass spectra were taken at $70 \mathrm{eV}$ with a scan interval of 0.5 seconds with a scan range of $40-1000 \mathrm{~m} / \mathrm{z}$. Total run time was 35 minutes. The relative percentage was calculated by comparing average peak to the total area. GC-MS solution version 2.53 software was used. The complete analysis was performed in Bureau Veritas, Ekattuthangal, Chennai, Tamil Nadu.

\section{Fourier transform infrared spectroscopy (FTIR)}

FTIR analysis of dried AgNP's was performed through potassium bromide pellet method [7] in the ratio of 1:100 with the help of Jasco FT/IR-6300 FTIR spectroscopy.

\section{DPPH radical scavenging method}

The assay was performed based on the protocol [9]. About $0.1 \mathrm{mM}$ DPPH was prepared by dissolving the chemical in methanol. Stock solutions of clove AgNP's were prepared at $10 \mathrm{mg} / \mathrm{ml}$ concentration. Varied concentrations $(0.05$ and $0.25 \mathrm{mg} / \mathrm{ml})$ of clove nanoparticles was made to react with DPPH solution for half an hour at $37^{\circ} \mathrm{C}$. Similar procedure was carried out for aqueous extract of clove $(0.05,0.1$, and $0.25 \mathrm{mg} / \mathrm{ml}$ ). BHA and DPPH were used as a positive and negative controls, respectively. The absorbance was measured using ultraviolet (UV)-visible double-beam spectrophotometer 1650pc (Shimadzu, USA) at $517 \mathrm{~nm}$. The test was performed in triplicates. Percentage scavenging was calculated using the formula give below,

DPPH radical scavenging activity $(\%)=[($ control sample-test sample)*100/control sample]

\section{Inhibition of protein denaturation}

The assay was performed based on the protocol [10]. Nearly $1 \%$ stock of bovine serum albumin (BSA) was prepared with doubledistilled water. A stock solution of clove nanoparticles was prepared at the concentration of $10 \mathrm{mg} / \mathrm{ml}$. The reaction mixture contained $0.5 \mathrm{ml}$ of BSA and different concentrations of clove extract $(0.05,0.1$, 0.15 , and $0.25 \mathrm{mg} / \mathrm{ml}$ ), which was incubated at room temperature for 15 minutes. Denaturation was induced by heating the reaction mixture at $60^{\circ} \mathrm{C}$ for 10 minutes and the absorbance was measured at $660 \mathrm{~nm}$ using a UV-visible spectrophotometer (Shimadzu pc1650, USA). Similar procedure was carried out for aqueous extract of clove $(0.05,0.1,0.15$, and $0.25 \mathrm{mg} / \mathrm{ml}$ ). BSA treated with aspirin and only BSA was considered as positive and negative controls, respectively. Percentage inhibition of denaturation was calculated using the formula give below:

$\%$ Inhibition $=[\text { negative control-test sample }]^{*} 100 /$ negative control

\section{Enzyme-linked immunosorbent assay (ELISA)}

Interleukin-1 beta was determined from cell culture supernatants using a commercially available ELISA kit (Bioassay technology) according to the protocol supplied with the kit. All samples were measured in duplicates.

\section{Molecular docking analysis}

In silico molecular docking, the study was performed using Schrödinger Maestro [11] to identify the anti-inflammatory property of aqueous extract of clove. Phytocomponents of clove were identified through GC-MS method. The two-dimensional (2D) compounds were retrieved from PubChem database [12] and then subjected to the LigPrep module of Schrödinger Maestro, where the compounds were converted from 2D to 3D, addition of hydrogens, generation of ionization states and assigning proper bond lengths, bond angles, torsion angles, correct chirality, stereochemistry, and ring conformation. The 2D X-ray coordinates of protein target beta-interleukin was downloaded from RCSB-protein data bank using the respective id: 2NVH [13]. Similar to ligand preparation, the protein was also minimized with the help of protein prep wizard in Schrödinger software. During energy minimization, hydrogen was added, assigning proper bond orders and ionization states along with charge fixing. Once the protein and ligand were energy minimized, a grid was generated to specify the active site region using glide grid module.

Further, extra precision (XP) virtual screening procedure was carried out to identify the best-docked compound based on glide energy, docking score, and active site interactions. Top 5 best-docked compounds were chosen induced fit docking (IFD) analysis, and the results were analyzed using ligand interaction module in Schrödinger maestro.

\section{RESULTS AND DISCUSSION}

Inflammation is one of the complex processes of an immune system, which acts in response to harmful stimuli, irritants, pathogens, and it is characterized by redness, pain, swelling, and warmth [14]. Conventional anti-inflammatory drugs produce undesirable side effects, which paved a way for the invention of safe alternatives. One such substitute is herbal medicine but due to their low shelf life and instability, it is not preferred widely. To improve the quality of herbal medicine, a combination of herbal extracts with the metal ions is practised in traditional medicines such as Siddha and Ayurveda. In our study, S. aromaticum extracts along with silver were formulated to form nanoparticles. The nanoparticles display entirely inimitable or enhanced properties based on specific characteristics such as size, distribution, and morphology [15]. AgNP's is unique among other metal nanoparticles and have received significant attraction among researchers because of their specific physical, chemical, and biological properties and their applications in medicine, cosmetics, and biomedical devices. Furthermore, AgNP's have been reported for antibacterial and antifungal activities [16]. It also possesses low toxicity when compared to other nanoparticles.

\section{GC-MS}

GC-MS results of clove aqueous extract showed a total of 15 compounds at different retention times (Table 1). The compound eugenol has the highest area percentage (66\%) at 9.52 minutes. The compounds from GC analysis were compared with national institute standard and technique (NIST08s) for structure determination.

GC-MS studies show that clove possesses unique aromatics with a higher percentage of eugenol.

\section{FTIR spectroscopy}

Clove AgNP's were characterized by FTIR analysis. The spectrum of clove AgNP's shows peaks in the range of 3400-3500, 2900, 1600-1500, and 1319 suggests that $\mathrm{OH}$, aldehydes, $\mathrm{NH}$ stretching, and the presence of ketones and amines. The spectrum also suggests that terpenoids, alcohols, ketones, and aldehydes surround AgNP's. The peak observed from the analysis confirms the reduction and capping of the synthesized clove AgNP's.

\section{DPPH radical scavenging assay}

Generation of free radicles damages tissues, which in turn induces an inflammatory response. Antioxidants donate hydrogen to satisfy the odd electron and subsides the activity of a free radical [17]. In this aspect, clove AgNP's and aqueous extract were studied for its antioxidant potential using DPPH scavenging assay. The antioxidant property of aqueous extract of clove and its nanoparticles were determined using 
DPPH assay and the results are shown in Fig. 1. Aqueous extract as well as AgNP's exhibited dose-dependent scavenging property. However, the nanoparticles of clove showed more scavenging activity, that is, $56 \%$ and $78 \%$ for the concentrations 0.05 and $0.25 \mathrm{mg} / \mathrm{ml}$, respectively, when compared with the aqueous extracts $(24 \%, 65 \%$, and $71 \%)$ at concentrations $0.05,0.1$, and $0.25 \mathrm{mg} / \mathrm{ml}$. From the results, it was inferred that clove AgNP's possess higher antioxidant when compared to aqueous extract.

\section{Inhibition of protein denaturation}

Protein denaturation is one of the causatives for inflammation. During this process, the proteins lose their quaternary structure thereby causes aggregation, which activates deleterious inflammatory signals [18]. In this aspect, the inhibition of protein denaturation by clove AgNP's and aqueous extract was investigated and shown in Fig. 2. From the results, it was inferred that the clove AgNP's, as well as aqueous extracts, exhibited concentration-dependent inhibition and the results were compared with the control drug aspirin. At $0.15 \mathrm{mg} / \mathrm{ml}$, clove nanoparticles showed $66 \%$ inhibition of denaturation when compared with the aqueous extract of clove (56\%) and aspirin (55\%).

\section{ELISA}

An elevated level of interleukin-1 beta cytokine was observed in various disorders such as arthritis, cancer, diabetes mellitus, and microbial infections. Downregulation of these cytokine decreases the progression and pathogenic effects of the disorders. In this regard, inhibition of this cytokine is an important pharmacological target for inflammatorybased disorders. The results revealed that clove AgNP's (Fig. 3) were able to inhibit the expression of interleukin-1 beta induced by Fenton's reagent by $80 \%$, whereas clove aqueous extract showed only $60 \%$ inhibition. The sample results were compared and quantified with

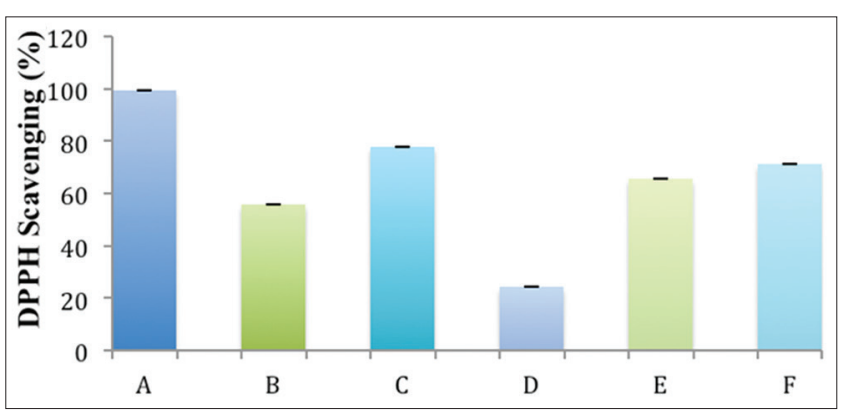

Fig. 1: 2, 2-diphenyl-1-picrylhydrazyl radical scavenging effects of aqueous and nanoparticles of clove extracts. Synthetic compound butylated hydroxyanisole (A) was used as a positive control at the concentration of $0.25 \mathrm{mg} / \mathrm{ml}$. B and $C$ represents $0.05 \mathrm{mg} / \mathrm{ml}$ and $0.250 \mathrm{mg} / \mathrm{ml}$ represents clove AgNP's, respectively. Aqueous clove extract at varied concentrations $0.05,0.1$, and $0.25 \mathrm{mg} /$ $\mathrm{ml}$ (D, E, F) was tested for its antioxidant property

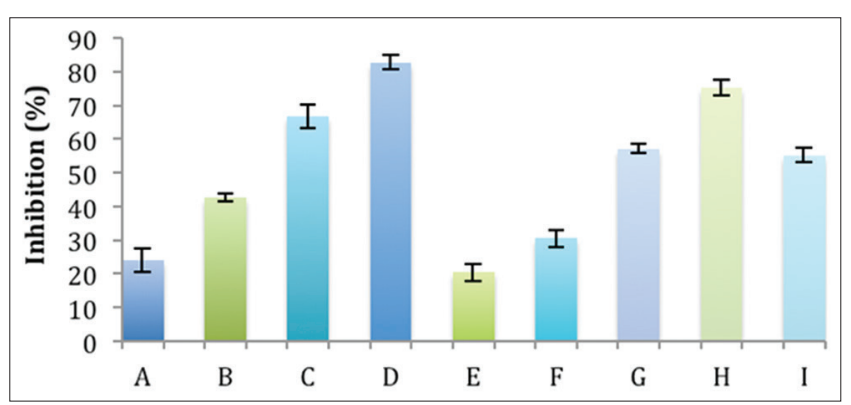

Fig. 2: Inhibition of protein denaturation by aqueous extract and nanoparticles of clove. A, B, C, and D represent clove AgNP's at $0.05,0.1,0.15$, and $0.25 \mathrm{mg} / \mathrm{ml}$, respectively. $\mathrm{E}, \mathrm{F}, \mathrm{G}$, and $H$ represent aqueous extracts of clove at $0.05,0.1,0.15$, and $0.25 \mathrm{mg} / \mathrm{ml}$, respectively. Aspirin (I) was used as a control control standard and Fenton's reagent-treated cells. From the optical density (Fig. 4), it was observed that the expressed interleukin-1 beta in Fenton's alone treated cells was found to be $30 \mathrm{ng} / \mathrm{L}$, whereas in clove AgNP's, the expression was $17.5 \mathrm{ng} / \mathrm{L}$, and thereby it can be concluded that clove AgNP's potentially inhibited interleukin expression induced by Fenton's reagent. This shows that AgNP's is an active antiinflammatory agent.

\section{Molecular docking analysis}

Molecular docking analysis was performed to identify the binding affinity of the phytocomponents of clove extract in the active site region of interleukin-1 beta. Based on the XP virtual screening results, five compounds, namely, methyl 14-methylpentadecanoate, betacaryophyllene, humulene, caryophyllene oxide, and eugenol were subjected to IFD studies.

The IFD results revealed that the compounds methyl 14-methylpentadecanoate and eugenol exhibited better binding affinity toward the interleukin-1 beta in terms of glide energy, docking score, and hydrogen-bonded interactions (Table 2). The compound methyl 14-methypentadecanoate showed hydrogen bond interactions with active site residues such as Glu50 and Asn 102 and hydrophobic interactions with active site residues such as Gln48, Pro57, Lys94, Lys92, Arg98, Met95, Glu96, Lys97, Val100, Gly49, Lys55, and Ala115 with glide energy: -29.607 and docking score: -2.401 . Another compound eugenol showed glide energy: -27.979 , docking score: -3.631, and hydrogen-bond interactions with Gln48 and Met95 along with hydrophobic interactions with Asn102, Pro57, Ala115, Glu50, Gly49, Lys97, Val100, Lys94, and Glu96 (Fig. 5). The binding affinity of the clove compounds was compared with the control drug mofezolac.

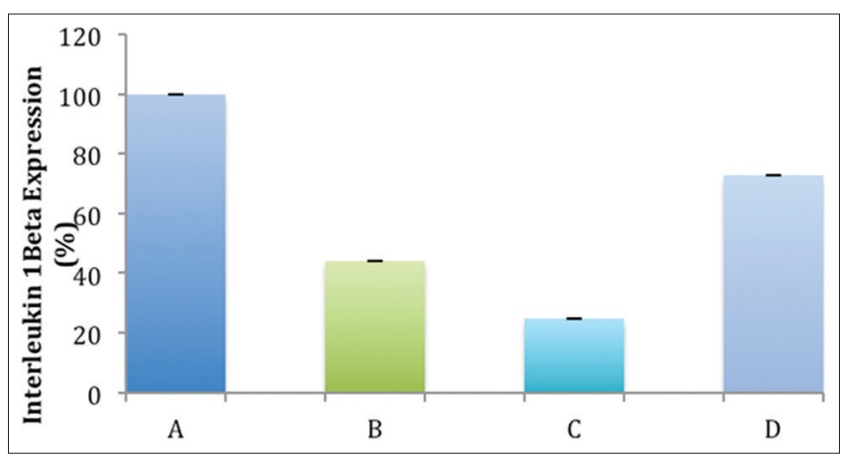

Fig. 3: Interleukin-1 beta expression in percentage was determined by enzyme-linked immunosorbent assay method for clove aqueous extract and nanoparticles. A represents standard provided with the kit, which shows $100 \%$ of interleukin-1 beta. $B$ and $C$ represent clove aqueous and nanoparticles at $0.05 \mathrm{mg} / \mathrm{ml}$. D represents positive control Fenton's reagent

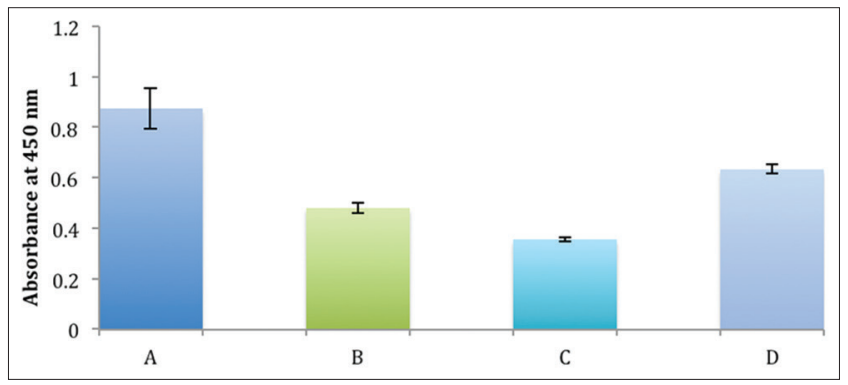

Fig. 4: Interleukin-1 beta expression (absorbance) was determined by enzyme-linked immunosorbent assay method for clove aqueous extract and nanoparticles. A represents interleukin standard (40 $\mathrm{ng} / \mathrm{L}$ ) provided with the kit. $B$ and $C$ represent clove aqueous and AgNP's at $0.05 \mathrm{mg} / \mathrm{ml}$. D represents cells treated with Fenton's reagent 
Table 1: GC-MS results of clove aqueous extracts

\begin{tabular}{lll}
\hline Compound & Rt & Area \% \\
\hline Phenol 4-,2propenyl & 8.210 & 0.39 \\
Alpha-cubebene & 9.525 & 0.37 \\
Eugenol & 9.718 & 66.46 \\
Copaene & 9.904 & 0.91 \\
Caryophyllene & 10.468 & 10.60 \\
Humulene & 10.892 & 1.58 \\
Ethanol 2-[2-(2 butoxyethoxy) ethoxy] & 11.040 & 0.34 \\
Gamma-muurolene & 11.137 & 0.63 \\
Alpha farnesene & 11.530 & 0.27 \\
Phenol, 2-methoxy-4-(2-propenyl)-acetate & 11.790 & 16.27 \\
Caryophyllene oxide & 12.466 & 0.49 \\
2',3',4'trimethoxyacetophenone & 13.640 & 0.54 \\
Hexadecanoic acid, methyl ester & 16.002 & 0.43 \\
14-pentadecenoic acid & 17.629 & 0.45 \\
1,2 Bis (trimethylsilyl) benzene & 26.507 & 0.26 \\
\hline
\end{tabular}

GC-MS: Gas chromatography-mass spectrometry

Table 2: IFD results of clove extracts against interleukin-1 beta

\begin{tabular}{lll}
\hline Compound name & $\begin{array}{l}\text { Docking } \\
\text { score }\end{array}$ & $\begin{array}{l}\text { Glide } \\
\text { energy (Kcal/mol) }\end{array}$ \\
\hline Methyl 14-methylpentadecanoate & -2.401 & -29.607 \\
Eugenol & -3.631 & -27.979 \\
Caryophyllene oxide & -3.320 & -24.076 \\
Humulene & -3.231 & -23.767 \\
Beta caryophyllene & -3.354 & -19.437 \\
Control (mofezolac) & -1.688 & -28.716 \\
\hline
\end{tabular}

IFD: Induced fit docking

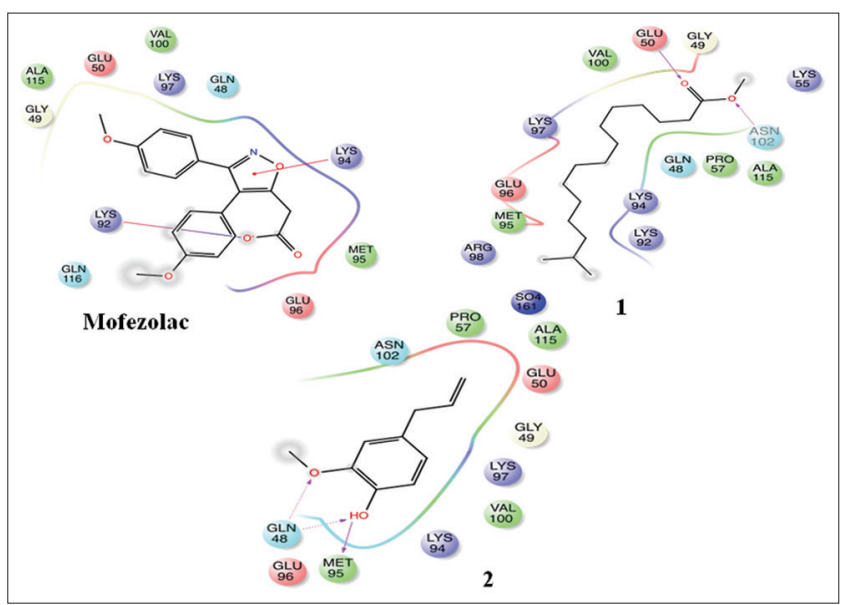

Fig. 5: The ligand interaction map showing hydrogen and hydrophobic interactions of the drug mofezolac and clove compounds (methyl 14-methylpentadecanoate (1) and eugenol (2)] against the active site region of protein interleukin-1 beta

The drug displayed glide energy: -28.716 , docking score: -1.688 , and the compound shown to possess salt bridge formation with Lys92 of the interleukin-1 beta.

\section{CONCLUSION}

The experimental findings of the above study demonstrated the synthesis of nanoparticles; antioxidant and anti-inflammatory properties of clove nanoparticles and aqueous extract. Hereby, from the above analysis, we conclude that clove AgNP's are a potent antioxidant, anti-inflammatory, and could be considered for drug discovery. Further investigations are mandatory to take it to the next level.

\section{REFERENCES}

1. Modi CM, Mody SK, Patel HB, Dudhatra GB, Avinash K, Madhavi A. Toxicopathological overview of analgesic and anti-inflammatory drugs in animals. J Appl Pharm Sci 2012;02(1):149-57.

2. Pan SY, Zhou SF, Gao SH, Yu ZL, Zhang SF, Tang MK, et al. New perspectives on how to discover drugs from herbal medicines: CAM's outstanding contribution to modern therapeutics. Evid Based Complement Alternat Med 2013;2013:627375.

3. Revathy SS, Murugesan M. Potentcy of kara sooda sathu parpam, a herbo mineral siddha drug in the managemnet of kalladaippu noi (Urolithiasis): A drug review. Int J Res Ayurveda Pharm 2014;5(3):372-9.

4. Charusheela R, Tapan C, Bijaya KS, Ram-Avatar P. Synthesis of silver nanoparticles from the aqueous extract of leaves of Ocimum sanctum for enchanced antibacterial activity. J Chem 2013;2013:1-7.

5. Cortés-Rojas DF, de Souza CR, Oliveira WP. Clove (Syzygium aromaticum): A precious spice. Asian Pac J Trop Biomed 2014;4(2):90-6.

6. Miguel MG. Antioxidant and anti-inflammatory activities of essential oils: A short review. Molecules 2010;15(12):9252-87.

7. Nagappan R. Evaluation of aqueous and ethanol extract of bioactive medicinal plant, Cassia didymobotrya (Fresenius) Irwin and Barneby against immature stages of filarial vector, Culex quinquefasciatus say (Diptera: Culicidae). Asian Pac J Trop Biomed 2012;2(9):707-11.

8. Mary EJ, Inbathamizh L. Green synthesis and characterization of nano silver using leaf extract of Morinda pubescens. Asian J Pharm Clin Res 2012;5(1):159-62.

9. Praba PS, Vasantha VS, Jeyasundari J, Brightson Y, Arul J. Synthesis of plant-medicated silver nanoparticles using Ficus microcarpa leaf extract and evaluation of their antibacterial activities. Eur Chem Bull 2015;4(3):117-20.

10. Tagashira M, Ohtake Y. A new antioxidant 1, 3-benzodioxle from Melissa officinalis. Planta Med 1998;64:555-8.

11. Rakesh W, Saranya S, Gurukarthikeyan, Kumar RP, Mari SS, Gayathri D, et al. Chitosan gallic acid microsphere incorporated collagen matrix for chronic wounds: Biophysical and Biochemical characterization. Int J Pharm Pharm Sci 2014;6(6):94-100.

12. Farid R, Day T, Friesner RA, Pearlstein RA. New insights about HERG blockade obtained from protein modeling, potential energy mapping, and docking studies. Bioorg Med Chem 2006;14(9):3160-73.

13. Kim S, Thiessen PA, Bolton EE, Chen J, Fu G, Gindulyte A, et al. Pub chem substance and compound databases. Nucleic Acids Res 2016;44(D1):D1202-3

14. Quillin ML, Wingfield PT, Matthews BW. Determination of solvent content in cavities in IL-1beta using experimentally phased electron density. Proc Natl Acad Sci U S A 2006;103(52):19749-53.

15. Deepa M, Renuka D. Potential anti-inflammatory medicinal plants-a review. Int J Pharm PharmSci 2014;6(4):43-9.

16. Husen A, Siddiqi KS. Phytosynthesis of nanoparticles: Concept, controversy and application. Nanoscale Res Lett 2014;9(1):229.

17. Lobo V, Patil A, Phatak A, Chandra N. Free radicals, antioxidants and functional foods: Impact on human health. Pharmacogn Rev 2010;4(8):118-26.

18. Leelaprakash G, Dass SM. In vitro anti-inflammatory activity of methanol extract of Enicostemma axillare. Int J Drug Dev Res 2011;3(3):189-6. 